\title{
Towards a new model exploring the effect of the human factor in Lean Management
}

\author{
Barbara Resta, Paolo Gaiardelli, Stefano Dotti, Roberto Pinto \\ CELS - Research Group on Industrial Engineering, Logistics and Service Operations, \\ Department of Management, Information and Production Engineering, viale Marconi 5, 24044, \\ Dalmine (BG), Italy \\ \{barbara.resta; paolo.gaiardelli; stefano.dotti; \\ roberto.pinto\} dunibg.it
}

\begin{abstract}
Although lean popularity is rapidly growing, its implementation is far from problem free and companies may experience difficulties sustaining long term success. In this paper, it is argued that the human behaviour, affected by the implementation of both hard (defined as technical and analytical tools) and soft lean practices (concerning people and relations), plays a key role in achieving long-term superior performance. Through a single case research, the relationships between lean practices implementation, human behaviour and operational performance are explored. From the analysis a new construct emerged, namely "Individual characteristics". As a result, an alternative research model for further statistical testing including individual behaviour as mediating variable and individual characteristics as moderating variable has been built.
\end{abstract}

Keywords. Lean Management, Human factor, Lean practices, Individual Behaviour (IB), Employees' Affective Attitude (EAA), Operational performance.

\section{Introduction}

The philosophy and practices associated with lean production have been around for many years, and have been applied in a number of settings including both discreteand process manufacturing environments, product development and to some extent services and product-services [1]. While there are great deals of lean success stories, a number of real cases has failed in achieving superior performance by applying a lean approach. Operations management (OM) scholars discussed several causes of this lack of success, many of which are indicative of the problems that arise in the human element during a changeover to lean [2]. As demonstrated by Veech [3], there is a fundamental difference between lean organizations and conventional organizations doing lean things: companies that fail in applying lean, fail in approaching and managing the human factor. It is not enough to just apply a lean principle or tool without a simultaneous strive for lean mind [4]. What is needed is a balanced whole system view that emphasizes improved performance through a focus on the persons delivering value to customers [5]. Thus, personal focus, involvement and motivation are 
imperative when applying lean principles: "Focus on the people and the results will follow. Focus on the results, and you'll have the same troubles as everyone else poor follow-up, lack of interest, no ownership of improvements, diminishing productivity" [6].

In such a context, many studies have focused on the requirements of lean in terms of hard practices (defined as technical and analytical tools) but they paid less attention towards the human factor and the soft practices (concerning people and relations) that could support a lean journey [7][8], and that can ensure positive results in both the long and the short term [9][10]. It is thus essential to monitor and "engineer" human performance in the same way as the performance of the production systems is engineered to achieve a superior performance through lean management [2].

This paper aims at contributing to fill this gap by exploring the effects of both soft and hard practice implementation on the human behaviour and the effects of human behaviour on operational performance, adopting a longitudinal perspective.

The paper is organised as follows. Section 2 presents the theoretical background of the study and the research conceptual framework. In Section 3, the research methodology will be described and the empirical study carried out in a manufacturing company will be presented. In Section 4, the research findings and implications are presented. Finally, the last section closes the paper with the most relevant conclusions and future research directions.

\section{Theoretical background}

\subsection{Human behaviour}

The human factor is a key element for the success of lean efforts as most of the reasons for lean failure can be linked directly or indirectly to the human element. Human behaviour has been formalised in ' 80 s by introducing the Individual Behaviour (IB) concept, defined as the attitude and actions or deeds of an individual working in an organization [11]. IB is affected by three factors, namely job satisfaction, commitment, and job stress, that represent the main components of the Employees' Affective Attitude (EAA) construct [12]. In previous research, soft practices has been shown as effective tools for the change of working climate, working methods, and working experiences [13], able to influence EAA during a lean implementation [14]. In particular, lean soft tools are argued to promote employee empowerment and group activity, which have a positive influence on job satisfaction and employees' loyalty [15]. A the same time, lean hard practices promotes resource optimization, reduction in variability of process, and defect free product leading to the improvement in performance, quality of work, and reduction in job stress [16]. Thus, the implementation of lean techniques in an organization can positively impact the three factors of EAA.

\subsection{Lean practices}

A systematic literature reviews reveals that different sets of soft practices have been put forward by different researchers. However, these practices can possibly be 
grouped into a finite number of generic categories, common in lean implementation in different organisations. The proposed categories are [17]: i) management leadership; ii) management support; iii) top management commitment; iv) organisational culture; v) communication; vi) training and skill building; vii) financial capability; and viii) measurement framework. Similarly, in accordance with Dennis [18], lean hard tools and techniques can be categorised into three main classes: stability and standardization, Just In Time (JIT) and Jidoka (quality). In general, the majority of empirical studies supports the overall positive direct impact of lean practices on firm's operational performance [19], without considering the key role of individual behaviour in maintaining such superior performance in the long term.

\subsection{Operational performance}

When measuring the impact of lean practices, different authors have tried to connect and reflect the combined effect of these practices into one operational indicator [20], now popularly known as "leanness". It include [21]: i) quality; ii) speed; iii) dependability; iv) flexibility; and v) cost.

The resulting research conceptual model is depicted in Figure 1.

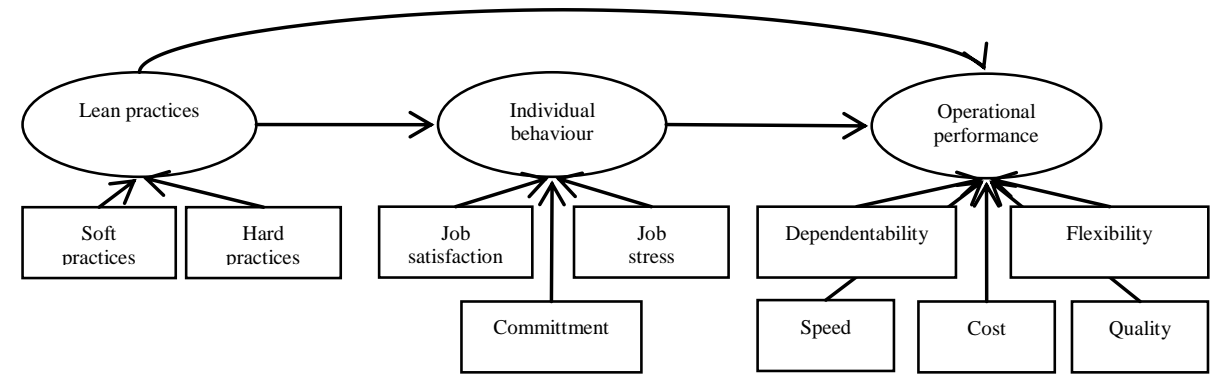

Fig. 1. The research conceptual model

\section{Research Methodology}

The paper is based on an exploratory case study conducted in company Alpha, a medium manufacturer of draft dispensing equipment for beer, wine, water and other soft drinks. The company, has recently expanded its production plants and has introduced a multi-year lean manufacturing project to continuously advance its production efficiency, drive out waste and increase the productivity of the whole supply chain. Based on the research conceptual model previously presented, a research protocol was designed and Alpha's management and operational employees were interviewed at two different times: before lean practice implementation and after 24 months from the 
beginning of lean practice implementation. A structured questionnaire consisting of four sections was adopted, to carry out the interviews.

- General information about the respondent (years of experience in Alpha, age, gender, education, main activity, type of contract, participation to lean practice implementation);

- Employees' Affective Attitude (EAA), addressed to operational workers, to assess their job satisfaction, commitment, and job stress on a 5-point Likert scale;

- Lean practices implementation, addressed to company's management, measured using a Likert scale $(1-5)$ to understand the level of adoption of soft and hard practices;

- Operational performance: addressed to company's management after lean practice implementation, to assess the performance improvement achieved after the implementation of lean practices.

Based on responses from 64 operational workers and 3 managers (representing the totality of Alpha's employees) at a single lean site, the authors explored the relationship between the degree of lean implementation (soft and hard practices) and workers' EAA, as well as the EAA effects on operational performance.

\section{$4 \quad$ Results and Discussion}

A short description of the main results is reported in the following.

\subsection{Lean practices implementation}

As summarised in Table 1, it emerges that the company has started to implement some hard practices, but it is still in a preliminary step of its lean transformation. In particular, Alpha's efforts have been mainly focused on developing techniques and methodologies that support process flow efficiency and effectiveness. Nevertheless, lean methodologies devoted to production quality improvement deserve further significant investments.

Table 1. Hard practices implementation

\begin{tabular}{|l|c|c|}
\hline & Before & After \\
\hline Stability and standardization & 0,00 & $2,17 / 5$ \\
\hline Jidoka (Quality) & 0,00 & $1,63 / 5$ \\
\hline Just In Time (JIT) & 0,00 & $2,99 / 5$ \\
\hline
\end{tabular}

Moreover, several soft practices have been applied to ease the success of lean implementation. In particular, as shown in Table 2, project goals and values have been set (Management Leadership), adequate resources and funding have been provided (Financial Capability) to create autonomy lean organisation, as well as to establish a system to properly plan, manage and measure process performances (Management Support and Measurement Framework) and to ensure those necessary mechanisms to 
enable a cultural change across the whole organisation (Organisational Culture). However, internal and external communication initiatives to convey consistent information about lean and to demonstrate visible top management commitment are still lagging behind.

Table 2. Soft practices implementation

\begin{tabular}{|l|c|c|}
\hline & Before & After \\
\hline Management leadership & 0,00 & $2,87 / 5$ \\
\hline Management support & 0,00 & $2,88 / 5$ \\
\hline Top management commitment & 0,00 & $1,88 / 5$ \\
\hline Organizational Culture & 0,00 & $2,56 / 5$ \\
\hline Communication & 0,00 & $1,67 / 5$ \\
\hline Training and Skill Building & 0,00 & $2,60 / 5$ \\
\hline Financial Capability & 0,00 & $3,06 / 5$ \\
\hline Measurement Framework & 0,00 & $3,33 / 5$ \\
\hline
\end{tabular}

\subsection{Individual behaviour}

The analysis of the 64 received responses that compose the total sample -whose main features are summarized in Table 3- underlines that the application of lean hard and soft practices have a positive impact on workers individual behaviour. Indeed, while both the satisfaction and the commitment increase, the level of stress remains nearly unchanged (Table 4). Moreover, the detailed analysis of the individual behaviour of each category characterising the sample suggests that:

- The higher the age and the years of experience in the company of the respondents the lower their satisfaction and commitment about lean manufacturing, whilst a direct relationship with stress emerges. Results underline the existence of a direct relationship between lean and cultural change and that lean approach encounters major difficulties if implemented in organisations, where the capabilities that have been acquired over time may limit management engagement in adaptive change.

- Different types of commitments emerge considering the educational level of respondents, their age, their work experience and the type of contracts. In particular, people with a primary school educational level subject to short term contracts present the highest level of commitment in doing activities. Young people with a very short experience, are characterised by a high level of commitment in taking operational decisions, while people with an high educational level declare having a very strong commitment in creating new solutions. Such results underline how lean manufacturing ease the cooperation at any level of the organisation, eliminate the cultural barriers, and stimulate vertical and horizontal information sharing.

- Satisfaction and commitment are higher in those departments where specific lean projects have been developed. Moreover, people involved in training activities and lean projects declare a major satisfaction, commitment and brand loyalty. Conversely, those workers and employees that have not participated at any lean project appear dissatisfied and not happy about the company. This result underlines how a 
right internal communication could avoid internal dissatisfaction especially of those people who are not been involved in lean initiatives.

Table 3. Respondents' characteristics

\begin{tabular}{|l|l|l|}
\hline Gender & Male & $75,00 \%$ \\
& Female & $25,00 \%$ \\
\hline Age & $<35$ & $13,06 \%$ \\
& between 35 and 45 & $55,69 \%$ \\
& $>45$ & $31,25 \%$ \\
\hline Years of experience in Alpha & $<2$ & $21,88 \%$ \\
& between 2 and 10 & $29,68 \%$ \\
& $>10$ & $48,44 \%$ \\
\hline Education & Primary School & $35,94 \%$ \\
& High School & $50,00 \%$ \\
& University & $14,06 \%$ \\
\hline Main activity/Department & Production & $55,93 \%$ \\
& Logistics & $15,25 \%$ \\
& Other departments & $28,82 \%$ \\
\hline Lype of contract & Long term & $81,25 \%$ \\
& Short term & $18,75 \%$ \\
\hline Lean experience & Yes & $14,06 \%$ \\
& No & $85,94 \%$ \\
\hline
\end{tabular}

Table 4. Individual behaviour measurement

\begin{tabular}{|l|c|c|l|c|}
\hline & \multicolumn{2}{|c|}{ Before } & \multicolumn{2}{c|}{ After } \\
\hline & Average & Std.dev/Average & Average & Std.dev/Average \\
\hline Satisfaction & $2,78 / 5$ & 0,47 & $3,27 / 5$ & 0,40 \\
\hline Commitment & $2,93 / 5$ & 0,51 & $3,29 / 5$ & 0,37 \\
\hline Stress & $1,72 / 5$ & 0,93 & $1,75 / 5$ & 0,93 \\
\hline
\end{tabular}

\subsection{Operational performance}

Looking at operational performances achieved through the application of lean initiative, interesting results emerge in terms of quality, time and costs (Table 5).

Table 5. Operational performance measurement

\begin{tabular}{|l|c|l|c|}
\hline & Average & & Variation \\
\hline Quality (Defects) & $-30 \%$ & Dependability & n.a. \\
\hline Speed (Lead Time) & $-30 \%$ & Flexibility & n.a. \\
\hline Speed (Cycle Time) & $-25 \%$ & Cost & $-20 \%$ \\
\hline
\end{tabular}




\subsection{Research finding and hypotheses}

Based on the results described above, a new construct emerged from the analysis, named "Individual characteristics" (Figure 2). How these relationships occur should be further analysed:

Hypothesis 1 - There is a positive relationship between lean practice implementation and individual behaviour, with the moderating effect of individual characteristics;

Hypothesis 2 - There is a positive relationship between individual behaviour and operational performance.

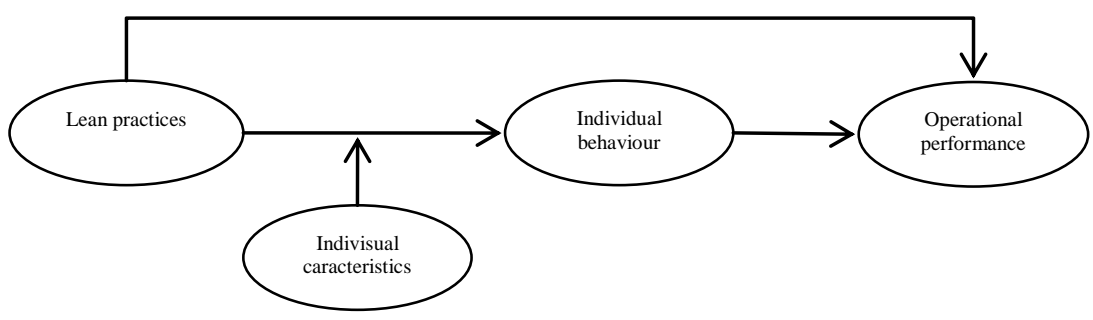

Fig. 2. New research model: Individual behaviour as mediating variable and individual characteristics as moderating variable

\section{Conclusion}

To achieve long-term benefits of a lean approach, a focus on individuals is an essential part. Empirical evidence from this study shows that the human behaviour, affected by the implementation of both hard (defined as technical and analytical tools) and soft lean practices (concerning people and relations), plays a key role in achieving longterm superior performance. Moreover, a new construct, named "Individual behaviour" and representing individuals' characteristics, emerged. As a result, two alternative research frameworks, for further statistical hypotheses testing, have been built. The research could also be further developed by measuring the operational performance dimension through quantitative key performance indicators (i.e., OEE, throughput time, WIP, etc.) and expanding the performance construct to other types of performance, in line with a triple bottom line approach (economic, environmental and social).

\section{References}

[1]. Resta, B., Powell, D., Gaiardelli, P., Dotti, S.: Towards a framework for lean operations in product-oriented product service systems. CIRP J. Manuf. Sci. Technol., doi:10.1016/j.cirpj.2015.01.008 (2015).

[2]. Sawhney, R., Chason, S.: Human behavior based exploratory model for successful implementation of lean enterprise in industry. Perform. Improv. Q. 18(2), 7696 (2005). 
[3]. Veech, D.S.: A person-centered approach to sustaining a lean environment-job design for self efficacy. Def. AR J. August-Nov (2004).

[4]. Liker J. K.: The Toyota Way: 14 management Principles from the World's Greatest manufacturer. McGraw-Hill, NY (2004).

[5]. Bicheno, J.: The new lean toolbox: towards fast, flexible flow. Production and Inventory Control, Systems and Industrial Engineering Books (2004).

[6]. Mann, D.: Creating a lean culture: tools to sustain lean conversions, Productivity press, NY (2005).

[7]. Dahlgaard, J. J., Dahlgaard-Park, S.: Lean production, six sigma quality, TQM and company culture. TQM Mag. 18(3), 263-281 (2006).

[8]. Bortolotti, T., Boscari, S., Danese, P.: Successful lean implementation: Organizational culture and soft lean practices. Int. J. Prod. Econ. 160, 182-201 (2015).

[9]. Hines, P., Holweg, M., Rich, N.: Learning to evolve: a review of contemporary lean thinking. Int. J. Oper. Prod. Manag. 24(10), 994-1011 (2004).

[10]. Matsui, Y.: An empirical analysis of just-in-time production in Japanese manufacturing companies. Int. J. Prod. Econ. 108(1), 153-164 (2007).

[11]. Arnett, R. C.: A choice-making ethic for organizational communication: The work of Ian I. Mitroff. J. Bus. Ethics 7(3), 151-161 (1988).

[12]. Rodwell, J. J., Kienzle, R., Shadur, M. A.: The relationship among work-related perceptions, employee attitudes, and employee performance: the integral role of communications. Hum. Resour. Manag. 37(3-4), 277-293 (1998).

[13]. Farris, J. A., Van Aken, E. M., Doolen, T. L., Worley, J.: Critical success factors for human resource outcomes in Kaizen events: An empirical study. Int. J. Prod. Econ. 117(1), 42-65 (2009).

[14]. Wiklund, H., Wiklund, P. S.: Widening the Six Sigma concept: An approach to improve organizational learning. Total Qual. Manag. 13(2), 233- 239 (2002).

[15]. Jun, M., Cai, S., Shin, H.: TQM practice in maquiladora: Antecedents of employee satisfaction and loyalty. J. Oper. Manag. 24(6), 791-812 (2006).

[16]. Shoaf, C., Genaidy, A., Karwowski, W., Huang, S. H.: Improving performance and quality of working life: A model for organizational health assessment in emerging enterprises. Hum. Factors Ergon. Manuf. Serv. Ind. 14(1), 81-95 (2004).

[17]. Kundu, G., Manohar, B. M.: Critical success factors for implementing lean practices in it support services. Int. J. Qual. Res. 6(4), 301-312 (2012).

[18]. Dennis, P.: Lean Production simplified: A plain-language guide to the world's most powerful production system. Productivity Press (2007).

[19]. Moyano-Fuentes, J., Sacristán-Díaz, M.: Learning on lean: a review of thinking and research. Int. J. Oper. Prod. Manag. 32(5), 551-582 (2012).

[20]. Bayou, M. E., de Korvin, A.: Measuring the Leanness of Manufacturing Systems - A Case Study of Ford Motor Company and General Motors. J. Eng. Technol. Manag. 25 (4), 287-304 (2008).

[21]. Belekoukias, I., Garza-Reyes, J. A., Kumar, V.: The impact of lean methods and tools on the operational performance of manufacturing organisations. Int. J. Prod. Res. 52(18), 5346-5366 (2014). 